\title{
Electrically conductive polydopamine-polypyrrole as high perfor- mance biomaterials for cell stimulation in vitro and electrical signal recording in vivo
}

\author{
Semin Kim ${ }^{1}$, Lindy K. Jang ${ }^{1}$, Minsu Jang ${ }^{1}$, Sanghun Lee ${ }^{1}$, John George Hardy ${ }^{2}$ and Jae Young Lee ${ }^{1,3^{*}}$ \\ ${ }^{1}$ School of Materials Science and Engineering, Gwangju Institute of Science and Technology, Gwangju 61005, Republic of \\ Korea \\ ${ }^{2}$ Department of Chemistry and Materials Science Institute, Lancaster University, Lancaster, Lancashire, LA1 4YB, United \\ Kingdom \\ ${ }^{3}$ Department of Biomedical Science and Engineering, Gwangju Institute of Science and Technology, Gwangju 61005, Re- \\ public of Korea
}

KEYWORDS polypyrrole; dopamine; bioelectrodes; electrical stimulation; conductive polymer

\begin{abstract}
Conductive polymers (CPs) such as polypyrrole (PPY) are emerging biomaterials for use as scaffolds and bioelectrodes which interact with biological systems electrically. Still, more electrically conductive and biologically interactive CPs are required to develop high performance biomaterials and medical devices. In this study, in situ electrochemical copolymerization of polydopamine (PDA) and PPY were performed for electrode modification. Their material and biological properties were characterized using multiple techniques. The electrical properties of electrodes coated with PDA/PPY were superior to electrodes coated with PPY alone. The growth and differentiation of $\mathrm{C} 2 \mathrm{C} 12$ myoblasts and PC12 neuronal cells on PDA/PPY was enhanced compared to PPY. Electrical stimulation of PC12 cells on PDA/PPY further promoted neuritogenesis. In vivo EMG signal measurements demonstrated more sensitive signals from tibia muscles when using PDA/PPY coated electrodes than bare or PPY coated electrodes, revealing PDA/PPY to be a high performance biomaterial with potential for various biomedical applications.
\end{abstract}

\section{Introduction}

Electrical signals play important roles in biological systems, such as electrical communication, ${ }^{1-3}$ wound healing, ${ }^{4-6}$ and embryonic development, ${ }^{7-9}$ inspiring research into the efficient mediation of electrical signals between biological tissues and medical devices (particularly for bioelectrodes to record or stimulate electrophysiological signals in live cells/tissues). To this end, electrically conductive polymers (CPs), which contain conjugated double bonds with delocalized $\pi$-orbitals, have been emerged as intermediating materials between bioelectrodes and biological system as they can intimately interact with biological systems rendering them interesting materials to modify bioelectrodes. ${ }^{10-15}$

CP-based biomaterials have been utilized to electrically stimulate electrically excitable cells/tissues can affect cellular behavior (e.g. proliferation and differentiation of various cells). ${ }^{16}$ ${ }^{19}$ For example, several reports successfully demonstrate promotion of neurite outgrowth of neuronal cells by electrical stimulation through conductive polymer scaffolds. In addition, $\mathrm{CP}$ modified electrodes can efficiently record electrophysiological signals in electrically excitable tissues (e.g., nerves and muscles), which benefit the diagnosis of pathological and physiological conditions. ${ }^{20-25}$ Among various conductive polymers, polypyrrole (PPY) is one of the most studied CPs for biomedical applications because of its good biocompatibility, high conductivity, ease of synthesis, and environmental stability. ${ }^{10,26-30}$
PPY modification of electrodes can dramatically lower electrical impedance by increasing surface areas and charge storage capacitance. ${ }^{31,32}$ PPY biomaterials has been further modified by creating specific topographies, incorporating biomolecules (e.g., peptides, proteins, and polysaccharides), and modulating mechanical properties to improve their biological interactions. $^{28,31,33,34}$

Despite the unique benefits of CP-modified electrodes, their biocompatibility is often compromised by electrochemical functions (e.g. thick CP coatings can decrease the electrical impedance of electrodes but lead to poor cell attachment and growth). The exact mechanism for this trade-off has not been systematically studied or reported yet. However, several proposed mechanisms have been discussed in the literature. For example, toxic monomeric and/or oligomeric units from the CPs may leach from the polymer matrices and thereby harm cells (problematic for thick CP coatings). Irregular and unstable features of thick CP may have negative effects on its interactions with cells. ${ }^{32,35}$ Hence the development of high performance CP coatings that have both good biological and electrical characteristics remains a challenge to their clinical translation. Dopamine and its analogues have been widely used to promote adhesion of various substances via various molecular interactions, such as hydrogen bonding, hydrophobic interactions, and aromatic-cationic interactions. We have previously reported the production of robust coatings of PDA/PPY on ITO (indium tin 
Scheme 1. A schematic of the electrochemical copolymerization (PDA/PPY) of dopamine and pyrrole and the use of PDA/PPY as a high performance biomaterial for cell-stimulating conductive scaffolds and highly sensitive bioelectrode applications.

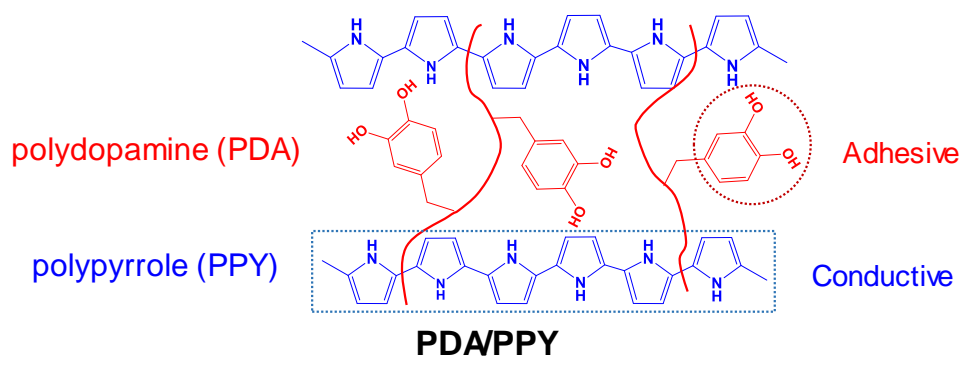

Bioactive conductive scaffolds

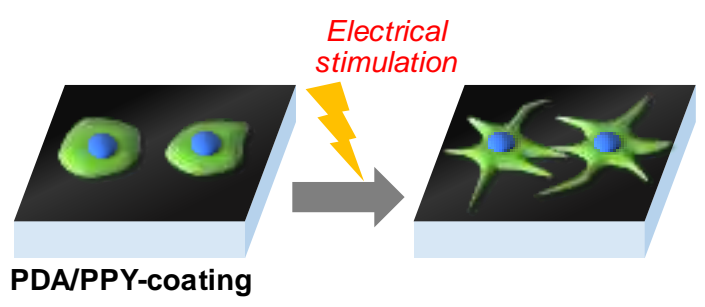

oxide) and gold electrodes via electrochemical copolymerization, which were uniform, adhesive, and conductive. ${ }^{35}$ Based on these findings, we hypothesized that PDA/PPY coatings can promote both the electrochemical and biological properties of electrodes and thus enhance the performances of conductive polymer biomaterials.

Here we report the results of our investigation of the interactions of PDA/PPY-modified electrodes with cells in vitro and in vivo (Scheme 1). We electrochemically deposited PPY or PDA/PPY on electrodes with different charges enabling us to vary the thickness and materials properties of these CP coatings. We validated the function of the materials in vitro through investigation of the growth and differentiation of PC12 neuronal cells and $\mathrm{C} 2 \mathrm{C} 12$ myoblasts on PDA/PPY, and of the potential for electrical stimulation of PC12 cells to potentially promote neuritogenesis. Furthermore, we validated the function of the novel PDA/PPY coated bioelectrodes to sense bioelectronic signals in vivo by recording electromyography (EMG) signals.

\section{Materials and Methods}

Materials: pyrrole, sodium chloride, aluminum oxide, dopamine hydrochloride, potassium hexacyanoferrate(III), and pottassium hexacyanoferrate(II) were purchased from Sigma-Aldrich (St. Louis, MO, USA). Dulbecco's modified Eagle's medium (DMEM) and fetal bovine serum (FBS) were obtained from Hyclone (Logan, UT, USA). Dulbecco's phosphate buffered saline (DPBS), F12K Kaighn's modification medium (F12K), horse serum (HS), antibiotic-antimycotic solution, and trypsin/EDTA were purchased from Gibco (Grand Island, NY, USA). Aelxa-fluor 488-conjugated phalloidin and DAPI were purchased from Invitrogen (Carlsbad, CA, USA). All other reagents and solvents were of analytical grade and used as received.

\section{Highly sensitive bioelectrodes}

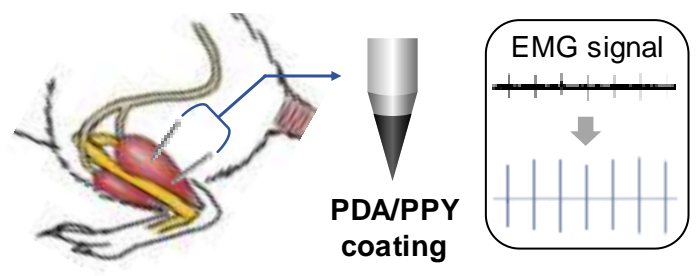

Electrochemical synthesis of PPY and PDA/PPY coatings: Pyrrole was purified by passing it through an aluminum oxide column before use. PDA/PPY films were prepared according to our previous report. ${ }^{35}$ In brief, the PDA/PPY polymerization solution was prepared to have $0.13 \mathrm{M}$ pyrrole, $26 \mathrm{mM}$ dopamine, and $0.1 \mathrm{M} \mathrm{NaCl}$ in deionized (DI) water at $\mathrm{pH}$ 6. Polymerization solution for PPY films was prepared to have $0.13 \mathrm{M}$ pyrrole and $0.1 \mathrm{M} \mathrm{NaCl}$ in DI water at $\mathrm{pH}$ 6. Individual PPY and PDA/PPY samples were electrochemically polymerized using a threeelectrode set-up using a VersaSTAT3 electrochemical working station (Princeton Applied Research) with a gold electrode as a working electrode, a platinum wire as a counter electrode, and a saturated calomel reference electrode (SCE, CH Instrument, Inc.). A current density of $1 \mathrm{~mA} \mathrm{~cm}^{-2}$ was applied to the electrolyte solution. Charges of 50,100, 200, $300 \mathrm{mC} \mathrm{cm}^{-2}$ were employed during the electrochemical PPY and PDA/PPY deposition, respectively, to prepare different electrodes of different thickness. The polymerized PPY and PDA/PPY were then carefully washed with DI water.

Characterization of $P P Y$ and $P D A / P P Y$ coatings: Atomic force microscopy (AFM, XE-100, Park System, Seoul, Republic of Korea) was used to characterize the surface topography. Substrates were scanned in a tapping mode with an NCHR tip (NCHR Nanoworld, Neuchâtel, Switzerland) at a scan rate of $0.3 \mathrm{~Hz}$. Roughness was calculated from the data by XEI software 4.3 (Park Systems, South Korea). Film thickness of the PPY and PDA/PPY were measured using the DEKTAK-XT stylus profiler (Bruker, Germany). Static water contact angles of the various PPY and PDA/PPY films were measured using a Phoenix 300 contact angle analyzer (Surface Electro Optics Co., Suwon, Republic of Korea). A $10 \mu$ L DI water droplet was placed on the surface of the substrates. Photographs were acquired and contact angles were measured. Electrochemical impedance spectra of the PPY or PDA/PPY-modified electrodes were obtained using VersaSTAT3 electrochemical working sta- 
tion with the three-electrode setup. A tape of a circular hole (inner diameter of $6 \mathrm{~mm}$ ) was attached onto the electrode surfaces to have the same exposed electrode areas $\left(0.283 \mathrm{~cm}^{2}\right)$ in all samples prior to electrochemical deposition. Impedances of the electrodes were measured in the solution $\left(5 \mathrm{mM}\left[\mathrm{Fe}(\mathrm{CN})_{6}\right]^{3-14-}\right.$ in PBS) with an amplitude of $5 \mathrm{mV}$ in a range of $0.1-10^{5} \mathrm{~Hz}$. A quartz crystal microbalance QCM (SEIKO EG \& G, Ltd., Japan) was used with on gold-coated crystals to monitor protein adsorption onto the PPY and PDA electrodes. Briefly, samples were mounted in a QCM flow cell and exposed to the solutions pumped at $100 \mathrm{~mL} \mathrm{~min}^{-1}$ for $1 \mathrm{~h}$. Solutions were flowed to the QCM cells in an order of PBS, $10 \%$ fetal bovine serum (FBS; in PBS), and PBS. A peristaltic pump (a low flow variable-flow peristaltic pump, Fisher scientific, MA) was used to pump the solution to the QCM crystal surface. The frequency changes were monitored by WinQCM software. Each adsorption experiment was performed three times.

In vitro cell culture studies: Mouse $\mathrm{C} 2 \mathrm{C} 12$ myoblasts were maintained on a tissue culture plate in growth medium (DMEM containing $10 \%$ FBS and $1 \%$ antibiotic-antimycotic solution) with $5 \% \mathrm{CO}_{2}$ at $37^{\circ} \mathrm{C}$. Culture media was exchanged every $3 \mathrm{~d}$ and cells were passaged with a $0.05 \%$ trypsin-EDTA solution at $90 \%$ confluence. $\mathrm{C} 2 \mathrm{C} 12$ cells were seeded on substrates at a density of $5 \times 10^{3}$ cells cm $\mathrm{cm}^{-2}$ and cultured for 3 and 7 days. After incubation, the samples were fixed in $3.7 \%$ paraformaldehyde at room temperature for $20 \mathrm{~min}$. The samples were then washed with DPBS. Next, the samples were incubated overnight at room temperature in permeabilizing/blocking solution $(0.1 \%$ Triton X100, 5\% BSA, and 5\% goat serum in DPBS) and then incubated overnight at $4{ }^{\circ} \mathrm{C}$ in rabbit anti-MHC antibody solution (MF-20, R\&D systems, 1:200 in the permeabilizing/blocking solution), and washed 3 times with DPBS. Next, the samples were incubated in Alexa Fluor 555-labeled goat anti-rabbit antibody solution (1:200 in the permeabilizing/blocking solution, Life Technologies) for $1 \mathrm{~h}$ at room temperature. The samples were then incubated with 4'-6-diamidino-2-phenylindole (DAPI) solution (1:1000 in DPBS) for $3 \mathrm{~min}$ at room temperature were washed three times with DPBS. For $F$-actin staining, the samples were incubated at room temperature for $20 \mathrm{~min}$ in Aelxa-fluor 488-conjugated phalloidin (1:200 in blocking solution, Invitrogen). The samples were washed with DPBS and then incubated in DAPI (1:2500 in DPBS) solution to stain nuclei.

PC12 neuronal cells were maintained in DMEM supplemented with $10 \%$ heat-inactivated horse serum, $5 \%$ FBS, and $1 \%$ antibiotic-antimycotic solution with $5 \% \mathrm{CO}_{2}$ at $37^{\circ} \mathrm{C}$. Prior to cell culture experiments, PC12 cells were primed by culturing them on collagen-coated tissue culture plate in the differentiation medium $(\mathrm{F}-12 \mathrm{~K}$ medium containing $1 \%$ heat-inactivated horse serum, $0.5 \% \mathrm{FBS}$, and $1 \%$ antibiotic-antimycotic solution) with $100 \mathrm{ng} \mathrm{mL}^{-1}$ soluble nerve growth factor (NGF, 2.5S, murine submaxillary gland, Promega, USA) one week prior to an experiment. For cell seeding, the samples were washed three times with sterile PBS for $1 \mathrm{~h}$. The primed PC12 cells were seeded on individual substrates at a density of $2 \times 10^{4}$ cells $\mathrm{cm}^{-}$ 2 and cultured for 3 and 5 days. After incubation, the samples were fixed in $3.7 \%$ paraformaldehyde at room temperature for $20 \mathrm{~min}$. The samples were then washed with DPBS. Cells were permeabilized in DPBS containing $0.1 \%$ Triton X-100 for 10 min and incubated in the blocking solution (2\% bovine serum albumin (BSA) in DPBS) for $2 \mathrm{~min}$. Then, $F$-actin staining was performed as described above. Fluorescence images were acquired using florescence microscope (DMI3000B, Leica, Germany).

Electrical stimulation of PC12: The effects of electrical stimulation of PC12 growing on the conductive substrates (i.e., PPY and PDA/PPY) on their neurite outgrowth were investigated using the electrical stimulation assembly prepared similarly to the previous literature. ${ }^{36}$ In brief, a polycarbonate well $(12 \mathrm{~mm}$ inner diameter) was placed on a PPY and PDA/PPY coated-electrode with medical glue. Three electrode systems were employed, in which a platinum mesh electrode and a silver wire electrode were used as a counter electrode and a reference electrode, respectively, while the PPY or PDA/PPY electrode was used as a working electrode. For electrical stimulation, $24 \mathrm{~h}$ after the seeding, PC12 cells were cultured in the NGFcontaining medium for $24 \mathrm{~h}$ and then stimulated with $100 \mathrm{mV}$ for $2 \mathrm{~h}$. Then, the cells were cultured for additional $24 \mathrm{~h}$.

Image analysis: Image analysis performed using ImageJ software (National Institutes of Health, Bethesda, MD, USA). Randomly acquired images were used for analysis. At least five samples were analyzed for each condition. Fusion index was defined as the percentage of nuclei present in the polynuclear microtubules containing two or more nuclei among all the nuclei in the field of view. ${ }^{37}$ For PC12 cells, neurite length was measured as a linear distance between the cell junction and the tip of neurite. Data was collected for neurite lengths greater than $10 \mu \mathrm{m}$. Cells with neurites longer than $10 \mu \mathrm{m}$ were identified as neurite-bearing cells.

In vivo electrophysiological measurement and histological assessment: All animal experiments were performed with permission from a committee on animal research and ethics in Gwangju Institute of Science and Technology (GIST), Republic of Korea. Adult female rats (Orient Bio Inc., South Korea) weighing approximately $350 \mathrm{~g}$ were used for EMG signal recording. The rats were anesthetized with $3 \%$ isoflurane solution (Ankuk Inc., Republic of Korea). Concentric needle electrodes were electrodeposited with PDA/PPY or PPY and further used for EMG recording. These electrodes were inserted into rat tibialis anterior. EMG signals were generated by stimulating of sciatic nerve using a Plexigals-platinum electrode with $0.7 \mathrm{~V}$. EMG signals and were recorded from the various needle electrodes with Biopac MP36 (Biopac Systems, Inc., CA, USA).

Histological assessment: To examine the tissue compatibility of PDA/PPY-modified electrodes, in vivo animal experiments were conducted with male BALB/c mice (six weeks old). PDA/PPY coated electrodes were sterilized by soaking in $70 \%$ ethanol for $1 \mathrm{~h}$, followed by thorough washing with DPBS. The mice were anesthetized with $2 \%$ isoflurane solution. After disinfection of shaved areas with $70 \%$ (v/v) ethanol, subcutaneous pockets were made to the right and left of a midline incision on the back. Two electrodes were implanted (one into each pocket) and the skin was sutured with silk thread. Three mice were used for samples. After four weeks, mice were sacrificed. Skin and muscle tissues containing an implant were embedded in paraffin. Paraffin-embedded tissue block was sectioned at $5 \mu \mathrm{m}$ thickness using a microtome. For histological analyses of tissue sections, hematoxylin and eosin (H\&E) (Sigma) staining was 
performed according to the literature ${ }^{27}$; samples were mounted in Canada balsam. Images of stained tissue samples were acquired using an optical microscope.

Statistical analysis: All tests were performed at least in triplicate and data were presented as the mean \pm standard deviation (SD) unless otherwise noted. Statistical significance was examined by one-way analysis of variance (ANOVA) with a Tukey's post-hoc comparison of the means using Origin software. A $p$ value less than 0.05 was considered to be statistically significant.

\section{Results}

3.1. Electrochemical fabrication and characterization of the electrodes.

PPY and PDA/PPY were electrochemically polymerized in a chronopotentiometric mode $\left(1 \mathrm{~mA} \mathrm{~cm}^{-2}\right)$ using either a pyrrole solution or a pyrrole/dopamine (1:0.2 molar ratio) solution, respectively. ${ }^{35}$ The electrochemical polymerization of the PPY and PDA/PPY was monitored (Figure 1a). The potentials during the polymerization of both polymers decreased and remained constant within $\sim 50 \mathrm{~s}$, which is indicative of the oxidative electrochemical polymerization of PPY and PDA/PPY on the surface of the electrodes. During the chronopotentiometric polymerization, PDA/PPY polymerization potential $(\sim 0.43 \mathrm{~V}$ vs SCE) was slightly lower than PPY polymerization potential $(\sim 0.68 \mathrm{~V})$, indicating the presence of dopamine facilitated the electrochemical polymerization process by acting as an electron mediator during the oxidative polymerization of pyrrole. ${ }^{35} \mathrm{Ad}-$ ditionally, electrode masses monitored by an electrochemical quartz crystal microbalance (EQCM) revealed the formation and growth of PPY and PDA/PPY films on the surface of the electrodes (Figure 1b). As the deposition time increased, the electrode masses concomitantly increased. Mass increases in
PPY-electrodes were higher than PDA/PPY-electrodes at the same current density $\left(1 \mathrm{~mA} \mathrm{~cm}^{-2}\right)$. For example, the mass increases after $300 \mathrm{mC}$ passage were $9.65 \mu \mathrm{g}$ and $8.29 \mu \mathrm{g}$ for PPY and PDA/PPY-electrodes, respectively. The thicknesses of the PPY and PDA/PPY coatings after electrodeposition with different charges was also measured (Figure 1c): the thickness of PPY or PDA/PPY layers were $92.7 \mathrm{~nm}$ or $63.4 \mathrm{~nm}$ for $50 \mathrm{mC}$ $\mathrm{cm}^{-2}, 196 \mathrm{~nm}$ or $89.7 \mathrm{~nm}$ for $100 \mathrm{mC} \mathrm{cm}^{-2}, 312 \mathrm{~nm}$ or $174 \mathrm{~nm}$ for $200 \mathrm{mC} \mathrm{cm}^{-2}$, and $453 \mathrm{~nm}$ or $200 \mathrm{~nm}$ for $300 \mathrm{mC} \mathrm{cm}^{-2}$, respectively. These trends were similar to the increases in the electrode's masses. The thicknesses (or masses) of PPY films were higher than those of PDA/PPY films when comparing the films prepared with the same deposition charges, which might be accounted for by the preferential formation of colloidal PDA/PPY particles in the polymerization solution in the vicinity of electrodes rather than deposition on their surfaces during electrochemical polymerization. ${ }^{35} \mathrm{We}$ can reproducibly obtain PPY electrode coatings (90 450 nm thick) and PDA/PPY electrode coatings $(60 \sim 200 \mathrm{~nm}$ thick) by varying the deposition time (i.e. charge passed). The electrochemical and biological performances of the coatings of various thicknesses were studied using various techniques. Examination by AFM (Figure 1d and 1e) showed the topographies of both PPY and PDA/PPY coatings were substantially affected by deposition charges (or thicknesses); thin coatings of both PPY and PDA/PPY were smooth, and increasing deposition charges resulted in coatings with rougher features. This was manifested as an increased frequency of large nodules for PPY-modified electrodes, whereas the PDA/PPY-coated electrodes remained relatively smooth without noticeable nodules (e.g., average roughness of 40.27 $\mathrm{nm}$ or $8.55 \mathrm{~nm}$ for the PPY films (at $300 \mathrm{mC}$ ) and the PDA/PPY films (at $300 \mathrm{mC}$ ), respectively). The smooth surface features of PPY/PDA might be attributed to the well-ordered polymerization of the PPY component (e.g., without pyrrole $\alpha-\beta$ coupling) and stabilized intermediates. ${ }^{38,39}$ The water contact angles of all of the PPY and PDA/PPY-coated electrodes were a

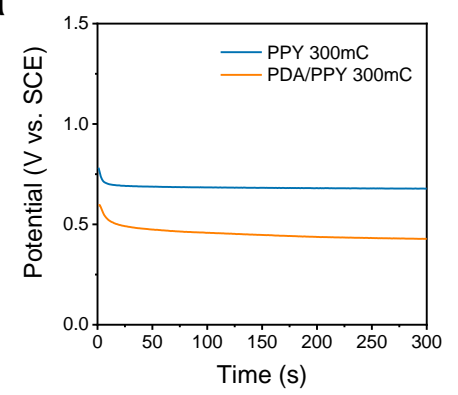

d

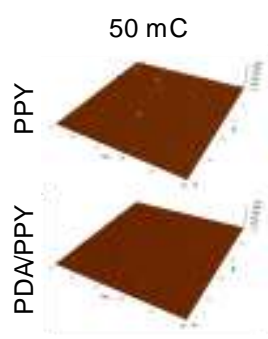

b

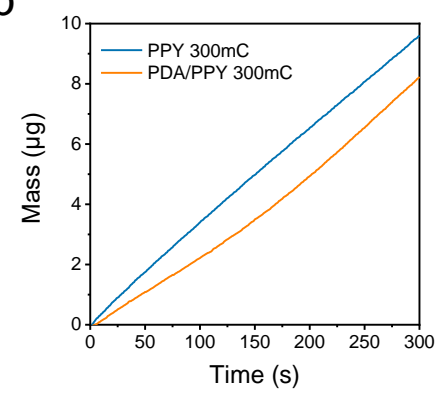

C

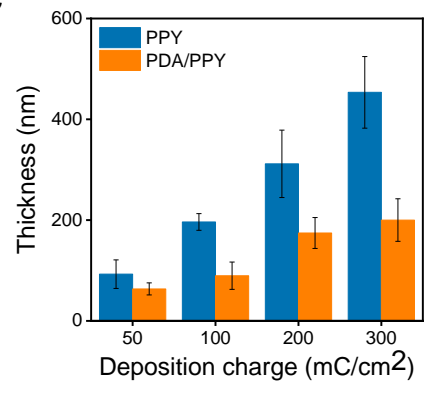

e

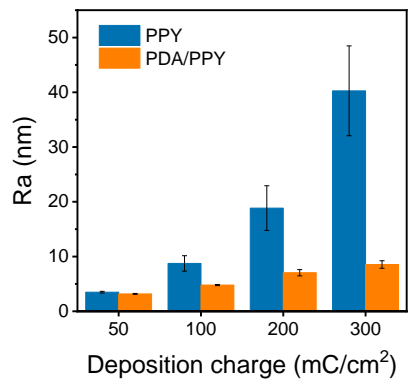

Figure 1. Synthesis and characterization of PPY and PDA/PPY-modified electrodes. (a) Potentials and (b) masses of electrodes during a chronopotentiometric polymerization $\left(300 \mathrm{mC} \mathrm{cm}^{-2}\right)$ for $300 \mathrm{~s}$. Electrochemical polymerization was conducted in the solutions containing pyrrole and pyrrole with dopamine, respectively. (c) Thicknesses of PPY and PDA/PPY layers prepared with different deposition charges. (d) Atomic force microscopic images of PPY and PDA/PPY deposited with current densities (50, 100, 200, and $\left.300 \mathrm{mC} \mathrm{cm}^{-2}\right)$. (e) Arithmetic average surface roughness of various PPY and PDA/PPY sample surfaces. 
$44^{\circ}$ with no statistically significant differences between the PPY and PDA/PPY samples (Supplementary Information Figure $\mathrm{S} 1$ ), and it is noteworthy that such moderately hydrophilic surfaces are suitable for biological interactions, such as protein adsorption and cell adhesion. ${ }^{40,41}$

3.2. Electrochemical properties of PPY and PDA/PPYmodified electrodes

The electrochemical impedances of the PPY - and PDA/PPYmodified gold electrodes were analyzed (Figure 2), observing significant decreases in impedances at all frequencies. As the thickness of the polymer coating increases, the impedances decreased dramatically, and the thickness-impedance plots at $1 \mathrm{~Hz}$ and $1 \mathrm{kHz}$ are displayed in Figure $2 \mathrm{c}$ and $2 \mathrm{~d}$. These frequencies (i.e., $1 \mathrm{~Hz}$ and $1 \mathrm{kHz}$ ) were chosen because they encompass the biologically important frequency range for electrical stimulation of muscle/nerve tissue and recording electrophysiological signals in vivo. ${ }^{42,43}$ Interestingly, the PDA/PPY electrodes exhibited significantly lower impedances compared to the PPY electrodes that had similar thicknesses, for example, the impedance of PPY $(50 \mathrm{mC})$ and PDA/PPY $(100 \mathrm{mC})$ at $1 \mathrm{~Hz}$ (which had thicknesses of $92.7 \mathrm{~nm}$ and $89.7 \mathrm{~nm}$, respectively) was $1114.37 \Omega$ and $571.61 \Omega$, respectively (Figure $2 \mathrm{c}$ and $2 \mathrm{~d}$ ). In addition, as PPY or PDA/PPY coating thickness increased, the impedances especially at low frequencies progressively decreased, which might be attributed to the increased capacitive properties of the electrodes. Conductive polymer coating could increase diffusive and/or double layer capacitance by increasing electroactive surface areas. ${ }^{44,45}$ Electrodes with low impedance polymer (PDA/PPY)-based coatings have great potential for application for electrical simulation and recording by ensuring efficient charge transfer between the electrode and cells/tissues.

a

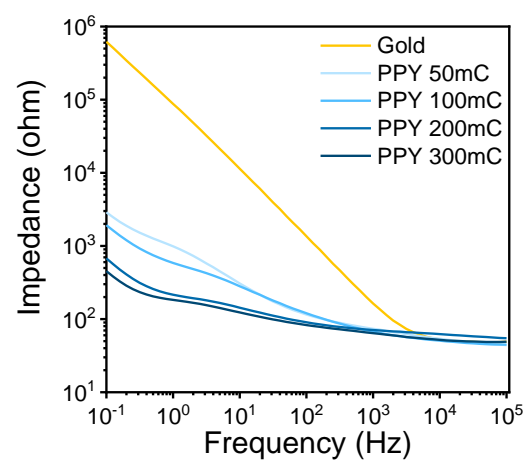

C

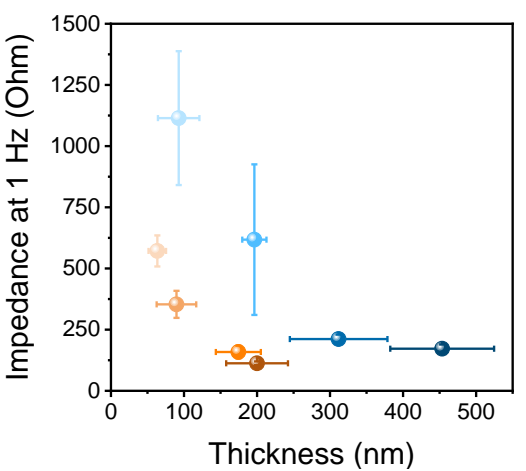

3.3. In vitro cell culture studies of PPY and PDA/PPYmodified electrodes.

The growth and differentiation of $\mathrm{C} 2 \mathrm{C} 12$ myoblasts and PC12 neuronal cells on PPY and PDA/PPY substrates with different thickness were studied in vitro. As shown in Figure 3, myoblast growth and differentiation on PPY substrates was relatively poor. For example, some cells were found only on the thin film (i.e., PPY $(50 \mathrm{mC}))$ and few cells on other thicker PPY samples at day 3 . This poor cell growth is frequently observed when using PPY-based materials. ${ }^{33}$ By comparison the PDA/PPY samples supported myoblast growth, with significantly more cells observed on PDA/PPY $(50 \mathrm{mC})$ compared to the other PDA/PPY samples prepared with $100 \mathrm{mC}, 200 \mathrm{mC}$, and $300 \mathrm{mC}$ charges. Myoblast numbers on the thin PPY and all PDA/PPY substrates increased over 7 days of culture. At 7 days of culture, the cells on PPY (50 mC), PPY $(100 \mathrm{mC})$, and all PDA/PPY samples reached confluence with approximately $220 \sim 300$ cells per image, suggesting that thin PPY films and all the tested PDA/PPY films were suitable substrates for myoblast growth. Comparing cell growth on PPY and PDA/PPY of the similar thicknesses, PDA/PPY films were found to support more cell attachment and faster growth than PPY films. When C2C12 myoblasts become confluent, they begin to differentiate into myotubes with morphological changes to form fused multinucleated cells expressing specific proteins, such as myosin heavy chain (MHC). ${ }^{46}$ MHC immunostaining revealed that the MHC expression of cells grown on all PDA/PPYcoated electrodes at day 7 was higher than that of cells grown on PPY-coated electrodes. Furthermore, we examined the fusion index of myoblasts cultured on different samples. Myoblast fusion is a typically important process in myognesis as

b

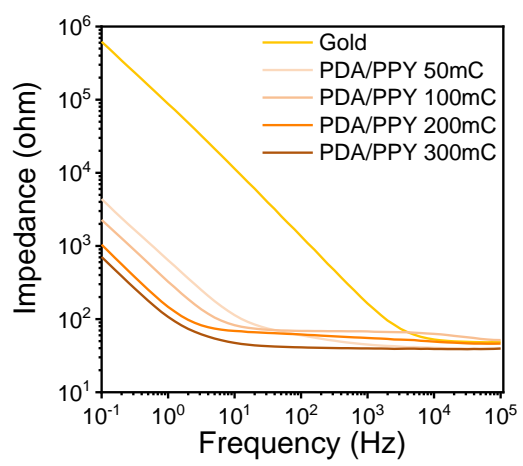

d

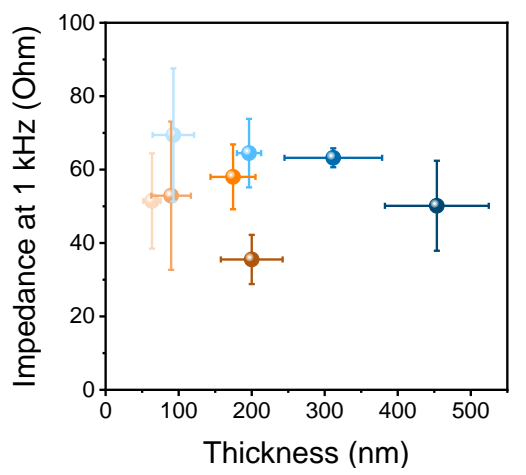

Figure 2. Characterization of electrochemical properties of PPY and PDA/PPY. Bode plots of (a) PPY and (b) PDA/PPY-modified gold electrodes prepared with different deposition charges. Impedance spectra were collected in a range of $10^{-1}-10^{5} \mathrm{~Hz}$, applying an a.c. sinusoidal signal at $5 \mathrm{mV}$ vs. SCE, in PBS solution. Thickness-impedance plots of PPY and PDA/PPY modified electrodes at (c) $1 \mathrm{~Hz}$ and (d) $1 \mathrm{kHz}$, respectively. 

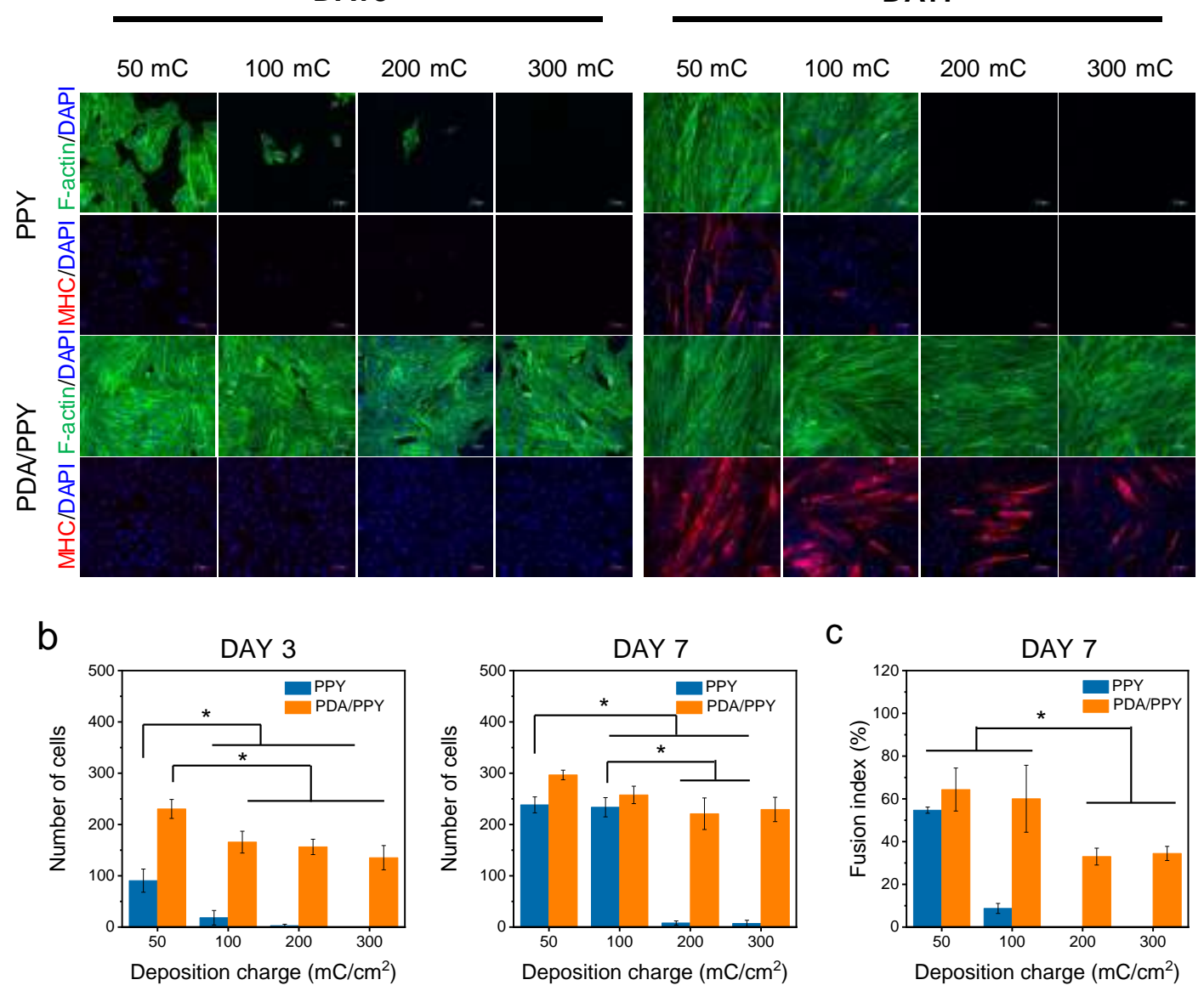

Figure 3. In vitro $\mathrm{C} 2 \mathrm{C} 12$ myoblast growth and differentiation on the PPY and PDA/PPY-modified electrodes. (a) Immunofluorescence images of $\mathrm{C} 2 \mathrm{C} 12$ cells cultured on PPY and PDA/PPY samples for 3 and 7 days. Cells were stained for $F$-actin (green), myosin heavy chain (MHC) (red), and nuclei (blue). Scale bars $=200 \mu \mathrm{m}$. (b) Number of cells at day 3 and day 7. (c) Fusion indices of the C2C12 myoblasts at day 7. For image analysis, images were randomly taken from multiple samples and analyzed. $n=5$.

myoblasts are fused to form multiinucleated myotubes and myofiber. ${ }^{47}$ The fusion index of the cells on thin PDA/PPY samples $(50 \mathrm{mC}$ and $100 \mathrm{mC}$ ) was significantly higher than on thick PDA/PPY (200 mC and $300 \mathrm{mC}$ ). Interestingly, PDA/PPY (200 $\mathrm{mC}$ and $300 \mathrm{mC})$ led to higher myogenesis than PPY $(100 \mathrm{mC})$, i.e. PDA/PPY-based materials are cell-adhesive conductive bioelectrodes that not only support myoblast growth but also myogenesis.

Moreover, PC12 neuronal cell growth on PDA/PPY electrodes was investigated (Figure 4). The numbers of PC12 cells were compared according to the electrode types (PPY and PDA/PPY) and film thicknesses. PC12 cells were homogeneously distributed and proliferated well on all of PDA/PPY films throughout 7 day culture. Thickness-cell number plots clearly demonstrate significant differences in cell numbers between PPY and PDA/PPY and their dependency of film thickness (Figure 4b). PC12 cells grew well only on PPY (50 mC) electrodes and other PPY samples did not permit cell adhesion and growth, with low cell numbers for 7 days. By comparison, more PC12 cells were observed on the thinner PDA/PPY electrodes at day 3 , and the cells on all the PDA/PPY reached confluency with similar cell numbers at day 7. Results from PC12 cell culture on PPY and PDA/PPY were similar to those obtained with C2C12 cells, i.e., PC12 cell adhesion and growth was better on PPY/PDA regardless of its thickness. As shown in Figure 4a,
PC12 cells showed neurites on thin PPY and all the PDA/PPY films (high confluency and rendered analysis of individual cells and neurites challenging).

Several studies have demonstrated enhanced neurite formation and/or elongation of neuronal cells after electrical stimulation of neuronal cells through various conductive materials. ${ }^{16,48,49}$ Accordingly, we validated the efficacy of the electrically conductive substrates to electrically stimulate neuronal cells and potentially promote neurite outgrowth. Electrical stimulation was performed using PPY (50 mC) and PDA/PPY (100 $\mathrm{mC}$ ), which have similar thickness (approximately $90 \mathrm{~nm}$ ), to avoid possible thickness-associated effects on neurite outgrowth (Figure 5). For unstimulated groups, neurite-bearing cell portions were not significantly different between the cells on PPY $(22.7 \pm 10.9 \%)$ and PDA/PPY $(24.3 \pm 6.9 \%)$. Electrical stimulation with PPY samples increased the neurite-bearing cell percentages from $22.7 \%$ to $31.9 \%$ ( $p=0.27$ ). Strikingly, PC12 cells on PDA/PPY showed a large promotion in neurite formation after electrical stimulation $(56.5 \pm 10.1 \%)$ compared to unstimulated controls $(24.3 \pm 6.9 \%)$. Electrical stimulation of PC12 cells also led to increases in mean neurite length from $12.6 \mu \mathrm{m}$ to $22.3 \mu \mathrm{m}$ for PPY films, and from $19.0 \mu \mathrm{m}$ to 28.3 $\mu \mathrm{m}$ for PDA/PPY films. Results indicate that neurite length was higher in the PDA/PPY groups than in the PPY groups in both the absence and presence of electrical stimuli. The neurites from 
a

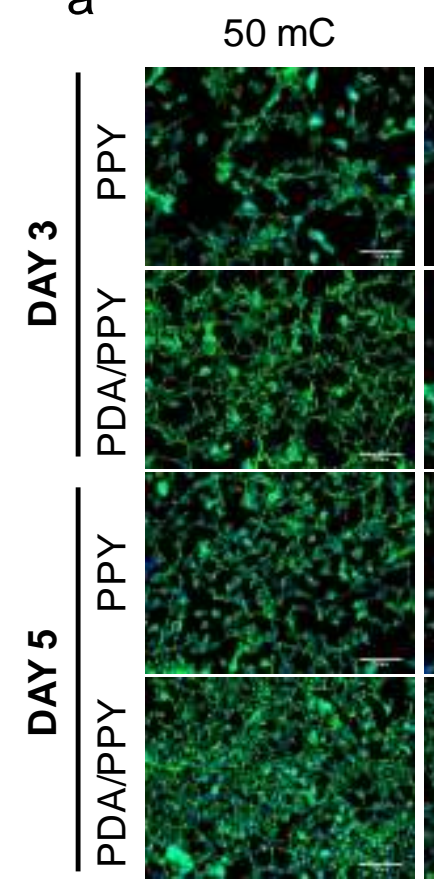

$100 \mathrm{mC}$
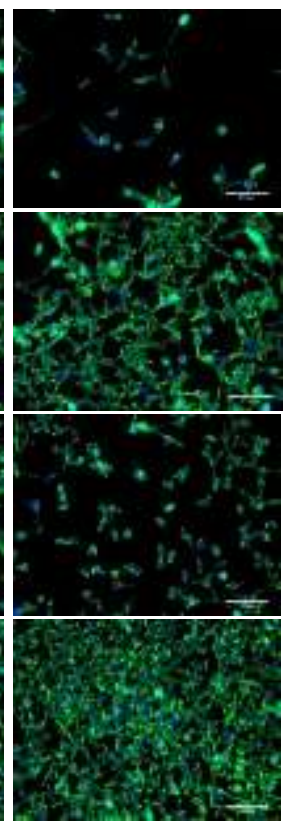

$200 \mathrm{mC}$
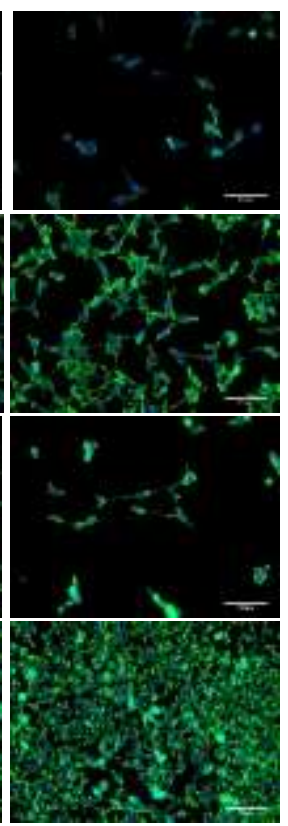

b

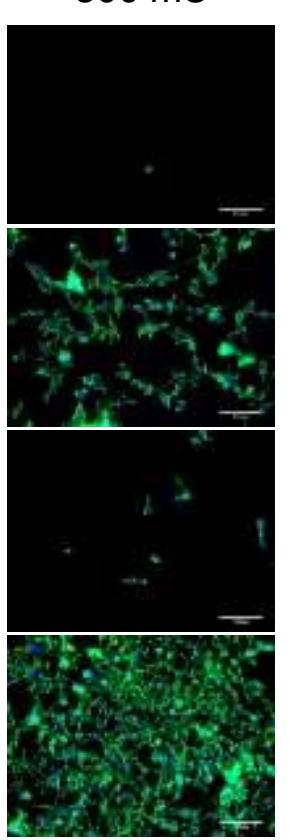

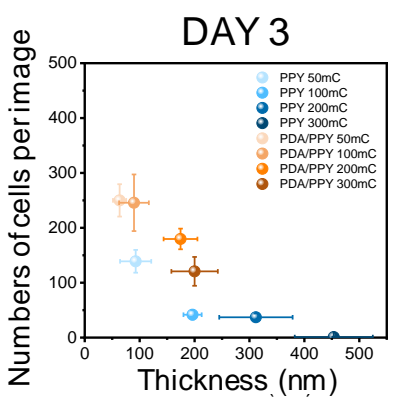

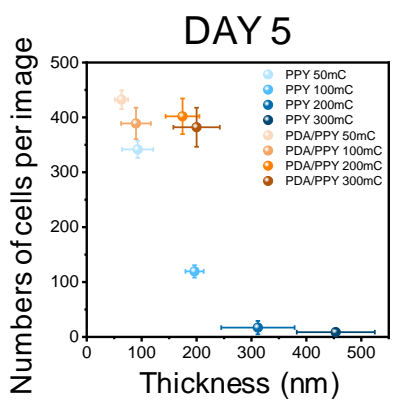

Figure 4. In vitro PC12 culture on the PPY and PDA/PPY-coated electrodes. (a) Immunofluorescence images of C2C12 cells cultured on PPY and PDA/PPY samples for 3 and 5 days. Cells were stained for $F$-actin (green) and nuclei (blue). Scale bars $=100 \mu \mathrm{m}$. (b) Numbers of cells on the substrates in the images at day 3 and day 5 depending on the thickness of the PPY and PDA/PPY films. Images were randomly acquired from multiple samples and analyzed. $n=5$.

a
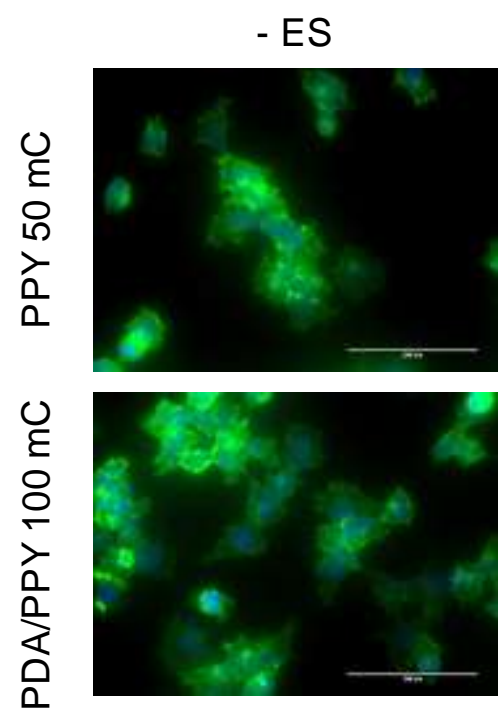

$+E S$
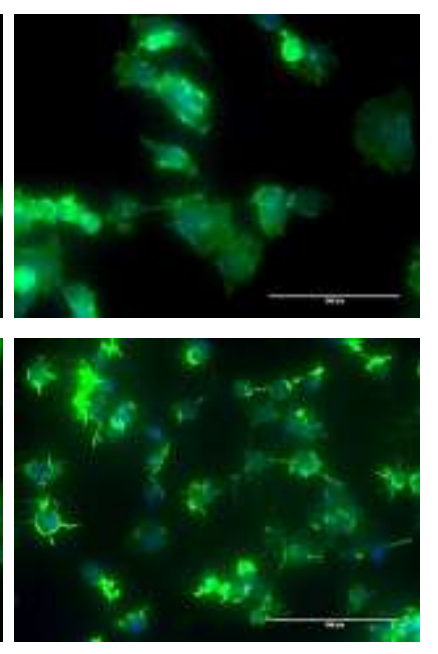

b
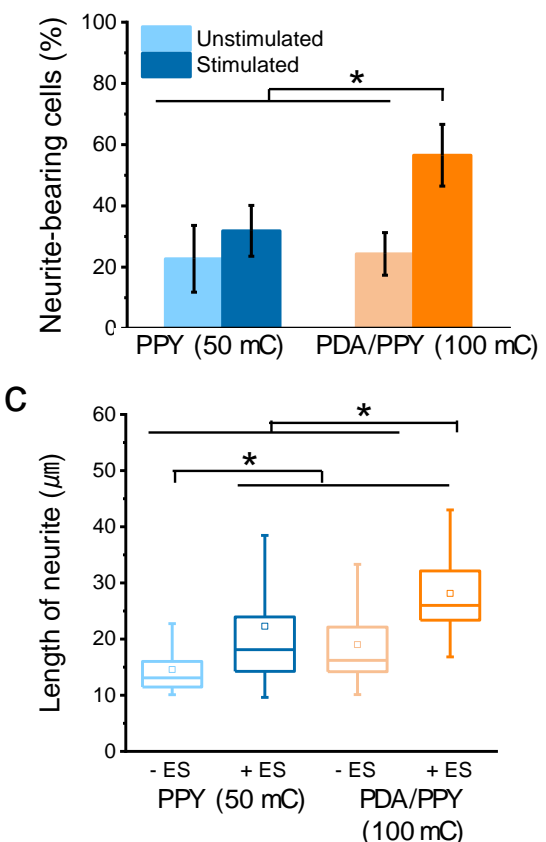

Figure 5. Electrical stimulation of PC12 cells on PPY $(50 \mathrm{mC})$ and PDA/PPY $(100 \mathrm{mC})$. (a) Florescence images of PC12 cells cultured on PPY $(50 \mathrm{mC})$ and PDA/PPY $(100 \mathrm{mC})$ in the absence (-ES) and presence (+ES) of electrical stimulation with $100 \mathrm{mV}$. (b) Neurite bearing cell percentages and (c) neurite lengths of PC12 cells. Images were randomly acquired from multiple samples and analyzed. At least 126 cells were analyzed for neurite formation and elongation.

PC12 cells grown on PDA/PPY (100 mC) with electrical stimulation were significantly longer than those from other groups. These results indicate that PDA/PPY can serve as an effective platform to induce neuritogenesis via electrical signals.
Growth and differentiation of myoblasts and neuronal cells could be affected by multiple factors. We postulated that protein adsorption might be attributed to the promoted cell growth and 

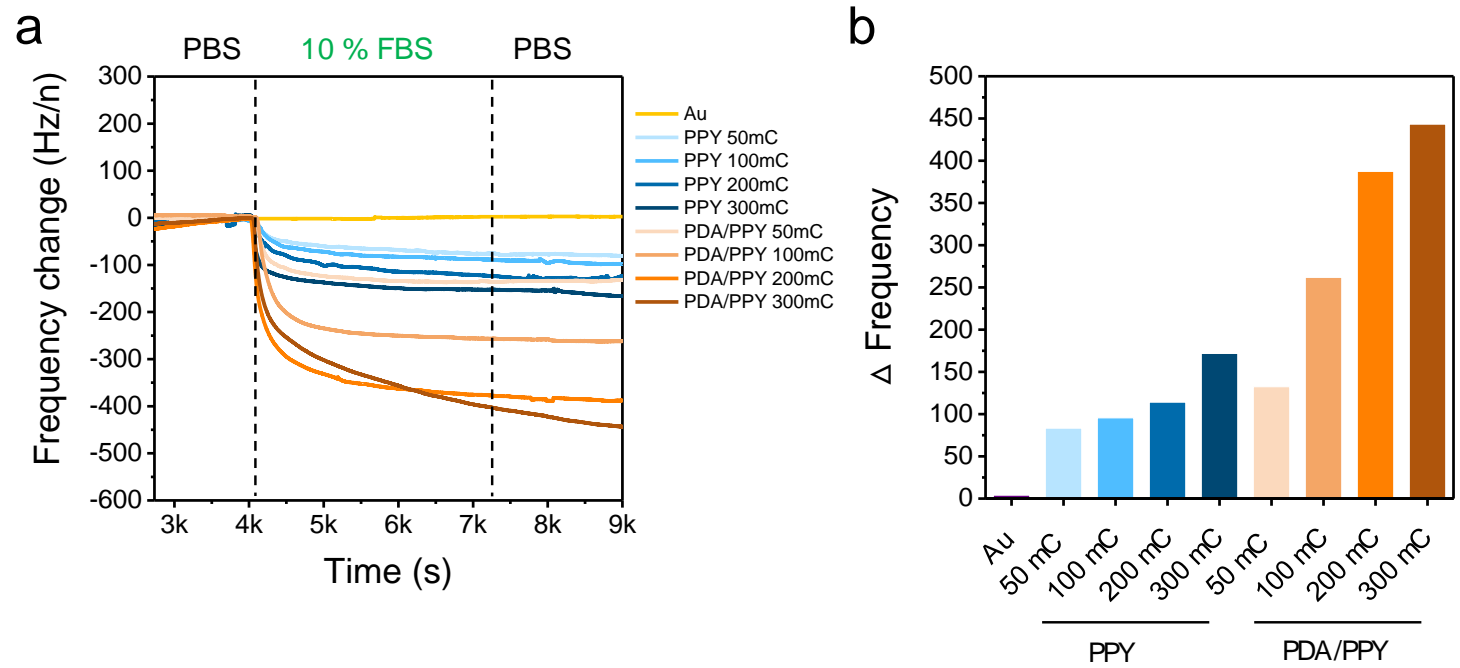

Figure 6. Protein adsorption on PPY and PDA/PPY-modified gold electrodes using a QCM. (a) Frequency change profiles of various gold, PPY, and PDA/PPY-modified electrodes during the incubation in 10\% FBS solution. Sample electrodes were exposed to PBS, followed by $10 \%$ FBS solution for $3000 \mathrm{~s}$ and rinse with PBS. (b). Frequency changes of the various electrodes, prepared with different deposition charges, after the incubation in $10 \%$ FBS for $1000 \mathrm{~s}$.

differentiation on the PDA/PPY because of its role in determining cellular adhesion and growth. Consequently, quartz crystal microbalance (QCM) experiments were conducted to monitor mass changes of PPY or PDA/PPY electrodes during incubation for $1 \mathrm{~h}$ in $10 \%$ fetal bovine serum (FBS) solution. As shown in Figure 6, while bare gold electrodes (used as a control substrate) did not show significant mass changes, protein adsorption was clear for both PPY and PDA/PPY films. Protein adsorption increased as the thickness of the coatings (PPY and PDA/PPY) increased, likely due to their increased surface roughness. Interestingly, more protein adsorption was found from the PDA/PPY substrates than the PPY substrates (typically1.5-3.4 times higher for PDA/PPY than PPY substrates prepared with the same deposition charges). These QCM experimental results suggest the dopamine and PDA in the PDA/PPY copolymer enhances serum protein adsorption and thereby supports cell growth and differentiation, which is consistent with the findings of previous studies that PDA can encourage protein adsorption and thus cell adhesion. ${ }^{50-53}$

\subsection{In vivo EMG measurement and tissue compatibility tests}

The function of the PDA/PPY-modified electrodes as implantable bioelectrodes was validated by measuring electromyography (EMG) in vivo. EMG signals were recorded from the concentric needle electrodes modified with PPY $(50 \mathrm{mC})$ or PDA/PPY $(100 \mathrm{mC})$ in the tibialis anterior while stimulating a sciatic nerve with a hook type electrode (Figure $7 \mathrm{a}$ and $7 \mathrm{~b}$ ). When a voltage pulse $(0.7 \mathrm{~V}$ at $1 \mathrm{~Hz})$ was delivered to the sciatic nerve of a rat, the hind limb muscle contracted and generated an EMG signal with an M-wave signal. EMG signals recorded from various electrodes (i.e., bare, PPY-coated, and PDA/PPYcoated) were compared. Peak-to-peak amplitudes were higher in the signals from the PDA/PPY-modified electrode (10.79 $\mathrm{mV})$ than those from the bare $(7.46 \mathrm{mV})$ and PPY-modified electrode $(7.47 \mathrm{mV}$ ) (Figure $7 \mathrm{c}$ ). The signal-to-noise ratio (SNR) gradually increased in the order of bare electrode (13.01 $\mathrm{dB})$, PPY-coated electrode $(27.97 \mathrm{~dB})$, and PDA/PPY-coated electrodes (37.67 dB) (Figure 7d). High quality signal record- ings from the PDA/PPY-modified electrodes might be attributed to effective charge transfers and low impedance. Our EMG signal recording experiments successfully demonstrated that our PDA/PPY modified electrodes were suitable for electrophysiological recording in vivo. In addition, the PDA/PPY coating remained intact on the electrode surfaces, as evident by the visual inspection of the retrieved electrodes (Supplementary Information Figure S2). For tissue compatibility tests, PDA/PPY (100 mC)-modified electrodes were subcutaneously implanted on male BALB/c mice for four weeks. H\&E staining revealed no significant inflammatory responses in the vicinity of the PDA/PPY implants (Figure 7e). Furthermore, no severe symptoms of severe inflammation around the implant sites (such as redness or yellow fluids) were observed, suggesting good tissue compatibility of the PDA/PPY electrodes and their suitability as implantable biomaterials.

\section{Discussion}

CPs, including PPY, are recognized as emerging biomaterials enabling efficient mediation of electrical signaling with biological systems and thereby important components to create functional tissue engineering scaffolds, bionic devices, and prosthetics. ${ }^{24,54-56}$ Despite their unique properties, several issues are unsolved. One important issue involves the combination of both good electrical properties and biocompatibility. As mentioned earlier, increases of the CP coating thickness offer improved charge capacitances and electrical conductance (admittance); however, concurrently cause impairment of mechanical stability (e.g., coating adhesion) and their biological ability to interact with cells. This trade-off has been commonly reported by several CPs, including PEDOT and PPY. ${ }^{32,57}$ Consequently, the development of $\mathrm{CP}$-deposition presenting both good electrical properties and cellular interaction by overcoming the trade-off limits is an appealing prospect. Therefore, we aimed to develop novel conductive materials presenting good electrical, mechanical, and biocompatible properties to leverage the utilities of $\mathrm{CP}$-based biomaterials for the applications as tissue scaffolds and bioelectrodes. 
a

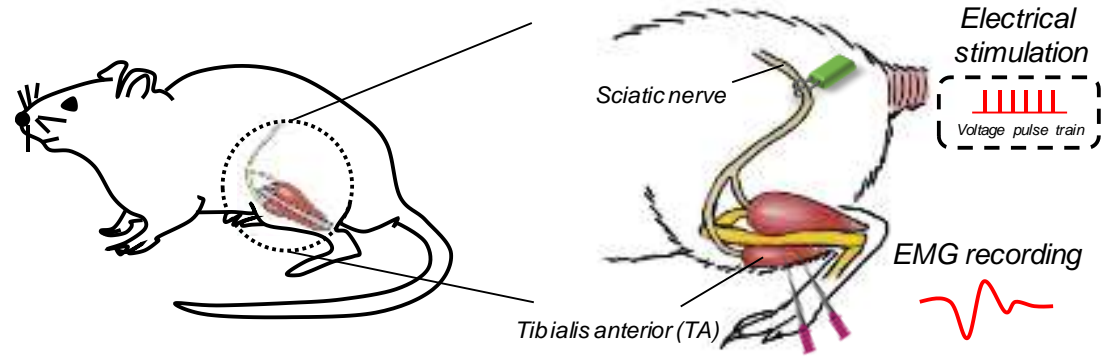

C

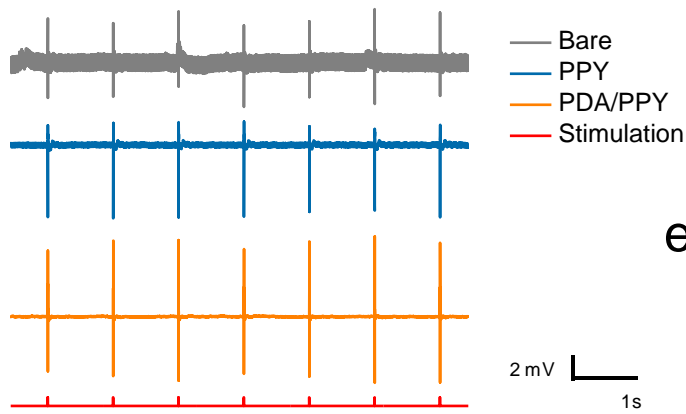

d
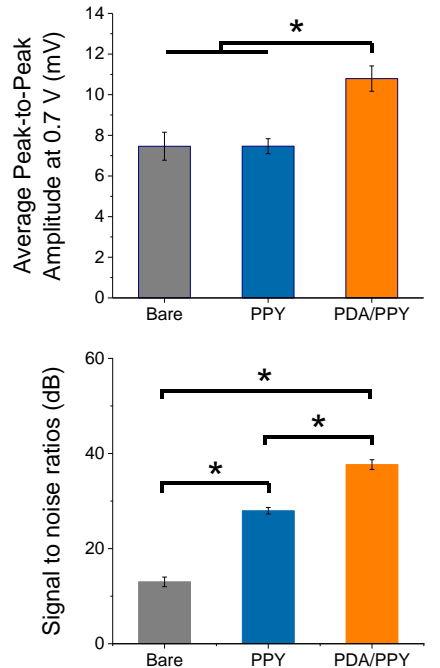

b

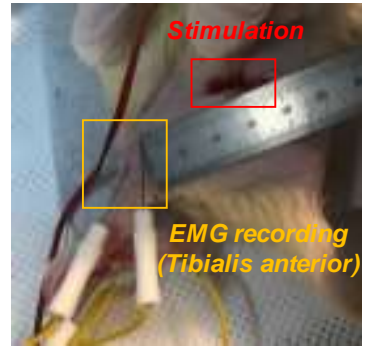

f
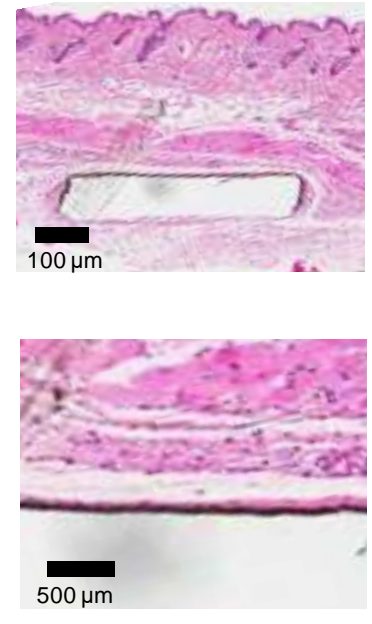

Figure 7. In vivo implantation of PDA/PPY-modified electrodes for electrophysiological measurement and tissue compatibility studies. (a) A schematic illustration of the electrophysiological EMG signal measurement at tibilalis anterior using a concentric needle electrode by stimulating sciatic nerve. (b) A photograph of animal experiments showing the stimulating hook electrode and the concentric needle electrode. (c) EMG signals recorded from a bare electrode, PPY, and PDA/PPY-coated electrodes. (d) Average peak-to-peak amplitudes and (e) signal-to-noise ratios (SNRs) obtained from EMG signals from different electrodes. (f) Micrographs of H\&E staining tissue section after 4 week implantation of PDA/PPY-modified electrode.

Dopamine is a key molecular moiety mimicking the adhesive components in adhesive foot in mussel byssus. ${ }^{58-60}$ Thus, dopamine and its analogues have been widely used to promote adhesion of various substances via various molecular interactions, such as hydrogen bonding, hydrophobic interactions, and aromatic-cationic interactions. ${ }^{61-63}$ Dopamine can be polymerized either by chemical or electrochemical oxidation, and the polymeric forms (PDA) exhibit great strength and affinity to various molecules/materials. Our previous studies demonstrated that in situ electrochemical copolymerization of pyrrole and dopamine and their deposition onto electrodes greatly improved mechanical adhesion and electrical performance of the electrodes. ${ }^{35}$

Based on these findings, we further attempted to explore the suitability of PDA/PPY to address above-mentioned trade-off issue and thus develop high performance biomaterials for scaffolds and bioelectrode applications. Importantly, comparison the electrical properties of PPY and PDA/PPY-modified electrodes of various thicknesses revealed that the PDA/PPY electrodes exhibited lower impedances compared to PPY electrodes that had similar thicknesses although the PDA/PPY generally had smoother surfaces PPY. This improved electrical property can be attributed to the enhanced adhesion of the conductive coating to electrode surfaces and well-organized polymeric structures between pyrrole units by minimizing random $\alpha-\beta$ coupling. ${ }^{38}$ Although we could observe the incorporation of PDA in the PDA/PPY films in our previous report ${ }^{35}$, the composition of the actual PDA/PPY could not be clearly analyzed due to the difficulties in similar atomic compositions and structures of the PPY and PDA. Accordingly, the future studies for the precise determination of the compositions of the PDA/PPY films will be necessary to understand and further improve the film properties.

In this present study, we first observed that PPY substrates of various thicknesses displayed a distinct trade-off trend; for instance, poor adhesion and growth on the thick PPY films. Conversely, PDA/PPY supported the growth and differentiation of $\mathrm{C} 2 \mathrm{C} 12$ myoblasts and PC12 neuronal cells. These results clearly indicate that PDA/PPY supports cell growth at variety of thicknesses. Cellular behaviors, such adhesion, growth, and differentiation, are strongly affected by surface roughness and protein adsorption. Comparison of cell growth on PPY and PDA/PPY substrates, which had with similar surface roughness, demonstrated the PDA/PPY is superior to PPY in supporting cell growth. For example, PDA/PPY $(200 \mathrm{mC})$ and PDA/PPY $(300 \mathrm{mC})$ showed better adhesion of myoblasts and neuronal cells compared to PPY $(100 \mathrm{mC})$ although they have similar surface roughness (implying that poor adhesion on PPY did not result from surface features). Our protein adsorption studies revealed that PDA in PDA/PPY greatly enhanced protein adsorption from 10\% FBS solution (in PBS). PDA/PPY $(200 \mathrm{mC})$ and PDA/PPY $(300 \mathrm{mC})$ absorbed 4-4.6 times higher mass increases compared to PPY $(100 \mathrm{mC})$ during $1 \mathrm{~h}$ of incubation in the 10\% FBS solution. Since protein adsorption, especially in serum-containing medium, plays an essential role in 
initial cell adhesion and growth, the promoted cell adhesion, growth, and differentiation on PDA/PPY are believed to result from the higher serum protein adsorption. Higher protein adsorption onto PDA/PPY can be explained by bio-adhesive dopamine moieties in PDA/PPY. ${ }^{50,64}$

Not only electrically excitable cells (e.g., neuronal cells and muscle cells) but also other cells (e.g., osteoblasts and stem cells) are reported to respond to electrical stimulation. In this study, electrical stimulation of PC12 cells was performed to examine possible promotion of neurite outgrowth for the demonstration of uses of the PDA/PPY biomaterials as scaffolds able to effectively modulate cellular responses by electrical stimulation. Electrical stimulation with PPY could slightly increase neurite formation and elongation in line with the literature. ${ }^{55}$ The electrical stimulation of PC12 cells via PDA/PPY led to significantly more and longer neurites than PPY groups and unstimulated groups. This suggests that PDA/PPY is an effective platform to effectively stimulate cells and thus efficiently affect cellular responses (growth and differentiation). Enhanced neurite outgrowth on PDA/PPY with electrical stimulation might be accounted for higher electrical conductivity and lower impedance that can afford efficient delivery of electrical signals to cells. Also, it is possible that the proteins, absorbed more and stably on the PDA/PPY, would play collaborative roles with electrical signals in induce neurite outgrowth.

For the demonstration of PDA/PPY-modified electrodes for potential in vivo applications as implantable bioelectrodes, we implanted the concentric needle electrodes in tibialis anterior of a rat and measured EMG signals while stimulating a sciatic nerve. PPY electrodes showed higher SNR than bare electrodes, but similar peak-to-peak amplitudes to the bare electrodes. More sensitive EMG signals with higher peak-to-peak amplitude and SNRs were obtained from the PDA/PPY than others. For example, SNRs of the EMG signals from the PDA/PPYelectrodes were 1.3 and 2.9 times higher than those from the PPY and bare electrodes, respectively. High quality EMG signals from the PDA/PPY electrodes result from the low impedance and strong adhesion of conductive layer on the electrode. Conductive polymer coatings often suffer from weak adhesion to electrode surfaces resulting in delamination and performance instability. ${ }^{65}$ Dopamine moieties in PDA/PPY are believed to enable the firm adhesion of PDA/PPY by avoiding its local delamination and possible instability. Histological inspection of the subcutaneous tissues implanted with PDA/PPY electrodes for 4 weeks demonstrated the good tissue compatibility. Various CPs have been utilized as implantable biomaterials (e.g., neural electrodes and scaffolds), which usually exhibited moderate-to-good tissue responses. ${ }^{20,66,67}$ Yet, some of the $\mathrm{CP}$ modified electrodes lose their electrical sensitivity after the implantation due to instability of the CPs and/or insufficient tissue compatibility. ${ }^{68-70}$ Our PDA/PPY is a promising electrochemically sensitive and tissue-compatible biomaterial for the development of high performance bioelectrodes.

\section{Conclusion}

With the aim of developing high performance conductive biomaterials, we employed electrochemical polymerization of pyrrole and dopamine. The PDA/PPY-modified electrodes exhibited excellent electrical and biological properties compared to PPY-modified electrodes. Especially, modification of PDA/PPY could address a typical trade-off issue between elec- trical properties and biological compatibility as PDA/PPY presented good electrochemical and cell-supporting characteristics even when thick layers were deposited on electrodes. Our series of in vitro cell culture experiments demonstrated that PDA/PPY significantly encouraged growth and differentiation of $\mathrm{C} 2 \mathrm{C} 12$ myoblasts and PC12 neuronal cells. Electrical stimulation of PC12 using PDA/PPY-modified electrodes showed the further promotion of neurite outgrowth. In vivo experiments further demonstrated successful recording of high sensitive EMG signals from rats and good tissue compatibility. We believe that the PDA/PPY is a novel conductive biomaterial that enables good electrical and biological performances for potential use as multifunctional tissue engineering scaffolds and implantable bioelectrodes.

\section{ASSOCIATED CONTENT}

Supporting Information.

Water contact angles, Actual images in vivo EMG measurement in vivo, Impedance of the concentric needle electrodes with and without PDA/PPY modification, Optical microscope images of PPY, PDA/PPY-coated concentric electrodes before and after injection.

\section{AUTHOR INFORMATION}

\section{Corresponding Author}

* E-mail: jaeyounglee@ gist.ac.kr

\section{Author Contributions}

S.K. and J.L. designed the study; S.K. performed the study; L.K.J. and S.L. performed synthesis of the samples; M.J. performed QCM analysis; all authors participated in development and discussions; $\$$ These authors contributed equally.

\section{Notes}

The authors declare no competing financial interest.

\section{ACKNOWLEDGMENT}

This research was supported by the Basic Science Research Program (2016R1A2B4007172) and the Pioneer Research Center Program (2014M3C1A3053029) through the National Research Foundation of Korea (NRF) funded by the Ministry of Science, ICT \& Future Planning. This work was also supported by GIST Research Institute(GRI) grant funded by the GIST in 2018. JGH acknowledges the support of a Lancaster University Faculty of Science and Technology Early Career Internal Grant and a Royal Society Research Grant (RG160449). The authors thank Dr. Hyun S. Park (KIST) for the discussion of impedance results.

\section{ABBREVIATIONS}

$\mathrm{CP}$, conducting polymer; PPY, polypyrrole, PDA polydopamine, EMG electromyography; ITO, indium-tin-oxide; QCM, quartz crystal microbalance; PEDOT, poly(3,4-ethylenediowythiophene); $\mathrm{CV}$, cyclic voltammetry; AFM, Atomic force microscopy; WCA, Water contact angle.

\section{REFERENCES}

(1) Yu, C.; Wang, C.; Liu, X.; Jia, X.; Naficy, S.; Shu, K.; Forsyth, M.; Wallace, G. G. A Cytocompatible Robust Hybrid Conducting 
Polymer Hydrogel for Use in a Magnesium Battery. Adv. Mater. 2016 28 (42), 9349-9355.

(2) Kotwal, A.; Schmidt, C. E. Electrical Stimulation Alters Protein Adsorption and Nerve Cell Interactions with Electrically Conducting Biomaterials. Biomaterials 2001, 22 (10), 1055-1064.

(3) Williamson, A.; Ferro, M.; Leleux, P.; Ismailova, E.; Kaszas, A.; Doublet, T.; Quilichini, P.; Rivnay, J.; Rózsa, B.; Katona, G. Localized Neuron Stimulation with Organic Electrochemical Transistors on Delaminating Depth Probes. Adv. Mater. 2015, 27 (30), $4405-4410$.

(4) Zhao, M.; Song, B.; Pu, J.; Wada, T.; Reid, B.; Tai, G.; Wang, F.; Guo, A.; Walczysko, P.; Gu, Y. Electrical Signals Control Wound Healing through Phosphatidylinositol-3-OH Kinase- $\gamma$ and PTEN. Nature 2006, 442 (7101), 457-460.

(5) Bhang, S. H.; Jang, W. S.; Han, J.; Yoon, J.; La, W.; Lee, E.; Kim, Y. S.; Shin, J.; Lee, T.; Baik, H. K. Zinc Oxide Nanorod-Based Piezoelectric Dermal Patch for Wound Healing. Adv. Funct. Mater. 2017, 27 (1), 160347.

(6) Kai, H.; Yamauchi, T.; Ogawa, Y.; Tsubota, A.; Magome, T.; Miyake, T.; Yamasaki, K.; Nishizawa, M. Accelerated Wound Healing on Skin by Electrical Stimulation with a Bioelectric Plaster. Adv. Healthc. Mater. 2017, 6 (22), 1700465.

(7) Delalat, B.; Mierczynska, A.; Ghaemi, S. R.; Cavallaro, A.; Harding, F. J.; Vasilev, K.; Voelcker, N. H. Materials Displaying Neural Growth Factor Gradients and Applications in Neural Differentiation of Embryoid Body Cells. Adv. Funct. Mater. 2015, 25 (18), 2737-2744.

(8) Ryan, A. J.; Kearney, C. J.; Shen, N.; Khan, U.; Kelly, A. G.; Probst, C.; Brauchle, E.; Biccai, S.; Garciarena, C. D.; VegaMayoral, V. Electroconductive Biohybrid Collagen/Pristine Graphene Composite Biomaterials with Enhanced Biological Activity. Adv. Mater. 2018, 30(15), 1706442.

(9) Jin, Y.; Seo, J.; Lee, J. S.; Shin, S.; Park, H.; Min, S.; Cheong, E.; Lee, T.; Cho, S. Triboelectric Nanogenerator Accelerates Highly Efficient Nonviral Direct Conversion and in Vivo Reprogramming of Fibroblasts to Functional Neuronal Cells. Adv. Mater. 2016, 28 (34), 7365-7374

(10) Rivers, T. J.; Hudson, T. W.; Schmidt, C. E. Synthesis of a Novel, Biodegradable Electrically Conducting Polymer for Biomedical Applications. Adv. Funct. Mater. 2002, 12 (1), 33-37.

(11) Green, R. A.; Baek, S.; Poole-Warren, L. A.; Martens, P. J. Conducting Polymer-Hydrogels for Medical Electrode Applications. Sci. Technol. Adv. Mater. 2010, 11 (1), 014107.

(12) Fattahi, P.; Yang, G.; Kim, G.; Abidian, M. R. A Review of Organic and Inorganic Biomaterials for Neural Interfaces. Adv. Mater. 2014, 26 (12), 1846-1885.

(13) Zelikin, A. N.; Lynn, D. M.; Farhadi, J.; Martin, I.; Shastri, V.; Langer, R. Erodible Conducting Polymers for Potential Biomedical Applications. Angew. Chem. Int. Ed. 2002, 41 (1), 141-144.

(14) Li, X.; Zhao, T.; Sun, L.; Aifantis, K. E.; Fan, Y.; Feng, Q.; Cui, F.; Watari, F. The Applications of Conductive Nanomaterials in the Biomedical Field. J. Biomed. Mater. Res. A 2016, 104 (1), 322 339.

(15) Liao, C.; Zhang, M.; Yao, M. Y.; Hua, T.; Li, L.; Yan, F. Flexible Organic Electronics in Biology: Materials and Devices. $A d v$. Mater. 2015, 27 (46), 7493-7527.

(16) Gomez, N.; Schmidt, C. E. Nerve Growth Factor-immobilized Polypyrrole: Bioactive Electrically Conducting Polymer for Enhanced Neurite Extension. J. Biomed. Mater. Res. A 2007, 81 (1), 135149.

(17) Nishizawa, M.; Nozaki, H.; Kaji, H.; Kitazume, T.; Kobayashi, N.; Ishibashi, T.; Abe, T. Electrodeposition of Anchored Polypyrrole Film on Microelectrodes and Stimulation of Cultured Cardiac Myocytes. Biomaterials 2007, 28 (8), 1480-1485.

(18) Bonisoli, A.; Marino, A.; Ciofani, G.; Greco, F. Topographical and Electrical Stimulation of Neuronal Cells through Microwrinkled Conducting Polymer Biointerfaces. Macromol. Biosci. 2017, 17 (11), 1700128 .

(19) Zhang, J.; Neoh, K. G.; Kang, E. Electrical Stimulation of Adipose-Derived Mesenchymal Stem Cells and Endothelial Cells Cocultured in a Conductive Scaffold for Potential Orthopedic Applications. J. Tissue Eng. Regen. Med. 2017, 12(4), 878-889.
(20) Khodagholy, D.; Doublet, T.; Gurfinkel, M.; Quilichini, P.; Ismailova, E.; Leleux, P.; Herve, T.; Sanaur, S.; Bernard, C.; Malliaras, G. G. Highly Conformable Conducting Polymer Electrodes for in Vivo Recordings. Adv. Mater. 2011, 23 (36), H268-H272.

(21) Sessolo, M.; Khodagholy, D.; Rivnay, J.; Maddalena, F.; Gleyzes, M.; Steidl, E.; Buisson, B.; Malliaras, G. G. Easy-to-fabricate Conducting Polymer Microelectrode Arrays. Adv. Mater. 2013, 25 (15), 2135-2139.

(22) Khodagholy, D.; Doublet, T.; Quilichini, P.; Gurfinkel, M.; Leleux, P.; Ghestem, A.; Ismailova, E.; Hervé, T.; Sanaur, S.; Bernard, C. In Vivo Recordings of Brain Activity Using Organic Transistors. Nat. Commun. 2013, 4, 1575.

(23) Choi, S.; Lee, H.; Ghaffari, R.; Hyeon, T.; Kim, D. Recent Advances in Flexible and Stretchable Bio-Electronic Devices Integrated with Nanomaterials. Adv. Mater. 2016, 28 (22), 4203-4218.

(24) Green, R.; Abidian, M. R. Conducting Polymers for Neural Prosthetic and Neural Interface Applications. Adv. Mater. 2015, 27 (46), 7620-7637.

(25) Qi, D.; Liu, Z.; Liu, Y.; Jiang, Y.; Leow, W. R.; Pal, M.; Pan, S.; Yang, H.; Wang, Y.; Zhang, X. Highly Stretchable, Compliant, Polymeric Microelectrode Arrays for In Vivo Electrophysiological Interfacing. Adv. Mater. 2017, 29 (40), 1702800.

(26) Guo, L.; Ma, M.; Zhang, N.; Langer, R.; Anderson, D. G. Stretchable Polymeric Multielectrode Array for Conformal Neural Interfacing. Adv. Mater. 2014, 26 (9), 1427-1433.

(27) Yang, S.; Jang, L.; Kim, S.; Yang, J.; Yang, K.; Cho, S.; Lee, J. Y. Polypyrrole/Alginate Hybrid Hydrogels: Electrically Conductive and Soft Biomaterials for Human Mesenchymal Stem Cell Culture and Potential Neural Tissue Engineering Applications. Macromol. Biosci. 2016, 16 (11), 1653-1661.

(28) Aufan, M. R.; Sumi, Y.; Kim, S.; Lee, J. Y. Facile Synthesis of Conductive Polypyrrole Wrinkle Topographies on Polydimethylsiloxane via a Swelling-Deswelling Process and Their Potential Uses in Tissue Engineering. ACS Appl. Mater. Interfaces 2015, 7 (42), 23454-23463.

(29) Kleber, C.; Bruns, M.; Lienkamp, K.; Rühe, J.; Asplund, M. An Interpenetrating, Microstructurable and Covalently Attached Conducting Polymer Hydrogel for Neural Interfaces. Acta Biomater. 2017, $58,365-375$.

(30) Spearman, B. S.; Hodge, A. J.; Porter, J. L.; Hardy, J. G.; Davis, Z. D.; Xu, T.; Zhang, X.; Schmidt, C. E.; Hamilton, M. C.; Lipke, E. A. Conductive Interpenetrating Networks of Polypyrrole and Polycaprolactone Encourage Electrophysiological Development of Cardiac Cells. Acta Biomater. 2015, 28, 109-120.

(31) Gelmi, A.; Higgins, M. J.; Wallace, G. G. Physical Surface and Electromechanical Properties of Doped Polypyrrole Biomaterials. Biomaterials 2010, 31 (8), 1974-1983.

(32) Gilmore, K. J.; Kita, M.; Han, Y.; Gelmi, A.; Higgins, M. J.; Moulton, S. E.; Clark, G. M.; Kapsa, R.; Wallace, G. G. Skeletal Muscle Cell Proliferation and Differentiation on Polypyrrole Substrates Doped with Extracellular Matrix Components. Biomaterials 2009, 30 (29), 5292-5304.

(33) Jang, L. K.; Kim, S.; Seo, J.; Lee, J. Y. Facile and Controllable Electrochemical Fabrication of Cell-Adhesive Polypyrrole Electrodes Using Pyrrole-RGD Peptides. Biofabrication 2017, 9 (4), 045007.

(34) Shrestha, B. K.; Ahmad, R.; Shrestha, S.; Park, C. H.; Kim, C. S. Globular Shaped Polypyrrole Doped Well-Dispersed Functionalized Multiwall Carbon Nanotubes/Nafion Composite for Enzymatic Glucose Biosensor Application. Sci. Rep. 2017, 7 (1), 16191.

(35) Kim, S.; Jang, L. K.; Park, H. S.; Lee, J. Y. Electrochemical Deposition of Conductive and Adhesive Polypyrrole-Dopamine Films. Sci. Rep. 2016, 6, 30475.

(36) Kimura, K.; Yanagida, Y.; Haruyama, T.; Kobatake, E.; Aizawa, M. Electrically Induced Neurite Outgrowth of PC12 Cells on the Electrode Surface. Med. Biol. Eng. Comput. 1998, 36 (4), 493-498.

(37) Minami, K.; Kasuya, Y.; Yamazaki, T.; Ji, Q.; Nakanishi, W.; Hill, J. P.; Sakai, H.; Ariga, K. Highly Ordered 1D Fullerene Crystals for Concurrent Control of Macroscopic Cellular Orientation and Differentiation toward Large-scale Tissue Engineering. Adv. Mater. 2015, 27 (27), 4020-4026. 
(38) Zhang, W.; Pan, Z.; Yang, F. K.; Zhao, B. A Facile in Situ Approach to Polypyrrole Functionalization through Bioinspired Catechols. Adv. Funct. Mater. 2015, 25 (10), 1588-1597.

(39) Zhang, W.; Zhou, Y.; Feng, K.; Trinidad, J.; Yu, A.; Zhao, B. Morphologically Controlled Bioinspired Dopamine-Polypyrrole Nanostructures with Tunable Electrical Properties. Adv. Electron. Mater. 2015, 1 (11), 1500205.

(40) Israelachvili, J.; Wennerström, H. Role of Hydration and Water Structure in Biological and Colloidal Interactions. Nature 1996, 379 (6562), 219-225

(41) Kasemo, B. Biological Surface Science. Surf. Sci. 2002, 500 $(1-3), 656-677$.

(42) Ludwig, K. A.; Uram, J. D.; Yang, J.; Martin, D. C.; Kipke, D. R. Chronic Neural Recordings Using Silicon Microelectrode Arrays Electrochemically Deposited with a Poly (3, 4-Ethylenedioxythiophene)(PEDOT) Film. J. Neural Eng. 2006, 3 (1), 59-70.

(43) Tian, H.-C.; Liu, J.-Q.; Kang, X.-Y.; Tang, L.-J.; Wang, M.H.; Ji, B.-W.; Yang, B.; Wang, X.-L.; Chen, X.; Yang, C.-S. Enhanced Flexible Tubular Microelectrode with Conducting Polymer for MultiFunctional Implantable Tissue-Machine Interface. Sci. Rep. 2016, 6, 26910.

(44) Luo, X.; Weaver, C. L.; Zhou, D. D.; Greenberg, R.; Cui, X T. Highly Stable Carbon Nanotube Doped Poly (3, 4-Ethylenedioxythiophene) for Chronic Neural Stimulation. Biomaterials 2011, 32 (24), $5551-5557$.

(45) Fall, M.; Diagne, A.; Guene, M.; Della Volpe, C.; Bonora, P.; Deflorian, F.; Rossi, S. R. Electrochemical Properties and Electrochemical Impedance Spectroscopy of Polypyrrole-Coated Platinum Electrodes. Bull. Chem. Soc. Ethiop. 2006, 20 (2), 279-293.

(46) Tanaka, K.; Sato, K.; Yoshida, T.; Fukuda, T.; Hanamura, K.; Kojima, N.; Shirao, T.; Yanagawa, T.; Watanabe, H. Evidence for Cell Density Affecting C2C12 Myogenesis: Possible Regulation of Myogenesis by Cell-Cell Communication. Muscle Nerve 2011, 44 (6), 968-977.

(47) Hindi, S. M.; Tajrishi, M. M.; Kumar, A. Signaling Mechanisms in Mammalian Myoblast Fusion. Sci Signal 2013, 6 (272), re2re2.

(48) Schmidt, C. E.; Shastri, V. R.; Vacanti, J. P.; Langer, R. Stimulation of Neurite Outgrowth Using an Electrically Conducting Polymer. Proc. Natl. Acad. Sci. 1997, 94 (17), 8948-8953.

(49) Lee, J. Y.; Bashur, C. A.; Goldstein, A. S.; Schmidt, C. E. Polypyrrole-Coated Electrospun PLGA Nanofibers for Neural Tissue Applications. Biomaterials 2009, 30 (26), 4325-4335.

(50) Hecker, M.; Ting, M. S. H.; Malmström, J. Simple Coatings to Render Polystyrene Protein Resistant. Coatings 2018, 8 (2), 55.

(51) Ding, Y.; Yang, Z.; Bi, C. W.; Yang, M.; Zhang, J.; Xu, S. L.; Lu, X.; Huang, N.; Huang, P.; Leng, Y. Modulation of Protein Adsorption, Vascular Cell Selectivity and Platelet Adhesion by MusselInspired Surface Functionalization. J. Mater. Chem. B 2014, 2 (24), $3819-3829$.

(52) Chuah, Y. J.; Koh, Y. T.; Lim, K.; Menon, N. V.; Wu, Y.; Kang, Y. Simple Surface Engineering of Polydimethylsiloxane with Polydopamine for Stabilized Mesenchymal Stem Cell Adhesion and Multipotency. Sci. Rep. 2015, 5, 18162.

(53) Ku, S. H.; Ryu, J.; Hong, S. K.; Lee, H.; Park, C. B. General Functionalization Route for Cell Adhesion on Non-Wetting Surfaces. Biomaterials 2010, 31 (9), 2535-2541.
(54) Guimard, N. K.; Gomez, N.; Schmidt, C. E. Conducting Polymers in Biomedical Engineering. Prog. Polym. Sci. 2007, 32 (8-9), $876-921$.

(55) Evans, A. J.; Thompson, B. C.; Wallace, G. G.; Millard, R.; O'Leary, S. J.; Clark, G. M.; Shepherd, R. K.; Richardson, R. T. Promoting Neurite Outgrowth from Spiral Ganglion Neuron Explants Using Polypyrrole/BDNF-coated Electrodes. J. Biomed. Mater. Res. A 2009, 91 (1), 241-250.

(56) Wallace, G. G.; Moulton, S. E.; Kapsa, R. M.; Higgins, M. J. Organic Conducting Polymers. Org. Bionics 2012, 81-112.

(57) Baek, S.; Green, R. A.; Poole-Warren, L. A. The Biological and Electrical Trade-Offs Related to the Thickness of Conducting Polymers for Neural Applications. Acta Biomater. 2014, 10 (7), 30483058 .

(58) Li, L.; Yan, B.; Yang, J.; Chen, L.; Zeng, H. Novel MusselInspired Injectable Self-Healing Hydrogel with Anti-Biofouling Property. Adv. Mater. 2015, 27 (7), 1294-1299.

(59) Waite, J. H. Surface Chemistry: Mussel Power. Nat. Mater. 2008, 7 (1), 8-9.

(60) Lee, H.; Rho, J.; Messersmith, P. B. Facile Conjugation of Biomolecules onto Surfaces via Mussel Adhesive Protein Inspired Coatings. Adv. Mater. 2009, 21 (4), 431-434.

(61) Li, L.; Zeng, H. Marine Mussel Adhesion and Bio-Inspired Wet Adhesives. Biotribology 2016, 5, 44-51.

(62) Han, L.; Yan, L.; Wang, K.; Fang, L.; Zhang, H.; Tang, Y.; Ding, Y.; Weng, L.-T.; Xu, J.; Weng, J. Tough, Self-Healable and Tissue-Adhesive Hydrogel with Tunable Multifunctionality. NPG Asia Mater. 2017, 9 (4), e372.

(63) Mrówczyński, R.; Markiewicz, R.; Liebscher, J. Chemistry of Polydopamine Analogues. Polym. Int. 2016, 65 (11), 1288-1299.

(64) Fan, J.; Luo, J.; Chen, X.; Wan, Y. Polydopamine Meets Porous Membrane: A Versatile Platform for Facile Preparation of Membrane Adsorbers. J. Chromatogr. A 2016, 1448, 121-126.

(65) Ravichandran, R.; Sundarrajan, S.; Venugopal, J. R.; Mukherjee, S.; Ramakrishna, S. Applications of Conducting Polymers and Their Issues in Biomedical Engineering. J. R. Soc. Interface 2010, 7, S559-S579.

(66) Abidian, M. R.; Martin, D. C. Experimental and Theoretical Characterization of Implantable Neural Microelectrodes Modified with Conducting Polymer Nanotubes. Biomaterials 2008, 29 (9), 12731283.

(67) Han, L.; Lu, X.; Wang, M.; Gan, D.; Deng, W.; Wang, K.; Fang, L.; Liu, K.; Chan, C. W.; Tang, Y. A Mussel-Inspired Conductive, Self-Adhesive, and Self-Healable Tough Hydrogel as Cell Stimulators and Implantable Bioelectronics. Small 2017, 13 (2), 1601916.

(68) Green, R. A.; Lovell, N. H.; Wallace, G. G.; Poole-Warren, L. A. Conducting Polymers for Neural Interfaces: Challenges in Developing an Effective Long-Term Implant. Biomaterials 2008, 29 (24-25), $3393-3399$

(69) Boehler, C.; Oberueber, F.; Schlabach, S.; Stieglitz, T.; Asplund, M. Long-Term Stable Adhesion for Conducting Polymers in Biomedical Applications: IrOx and Nanostructured Platinum Solve the Chronic Challenge. ACS Appl. Mater. Interfaces 2016, 9 (1), 189-197.

(70) Balint, R.; Cassidy, N. J.; Cartmell, S. H. Conductive Polymers: Towards a Smart Biomaterial for Tissue Engineering. Acta Biomater. 2014, 10 (6), 2341-2353. 


\section{Table of Contents Graphic}

Highly performing conductive polymer-modified biomaterials were prepared by in situ electrochemical polymerization (PDA/PPY) of pyrrole and dopamine. The PDA/PPY-modified electrodes exhibit superior electrochemical and biological characteristics to conventional PPY electrodes. These conductive PDA/PPY biomaterials offer in vitro electrical stimulation of neuronal cells and in vivo EMG recording with good tissue compatibility.

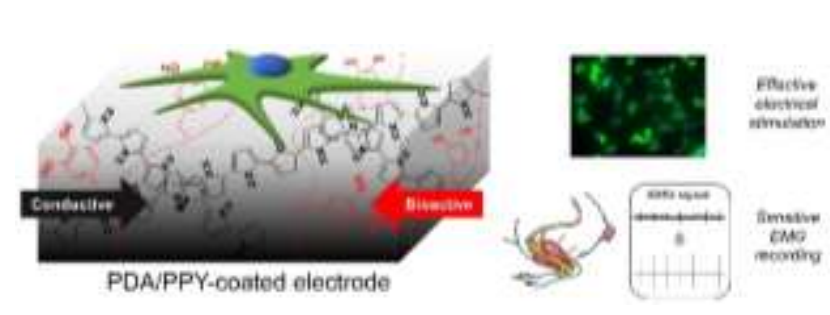

